\title{
TUNGSTEN OXIDES REDUCTION TECHNOLOGY ON A PLASMA PLANT
}

\author{
Nurmurodov S.D. ${ }^{1}$, Rasulov A.Kh. ${ }^{1}$, Allanazarov A.A. ${ }^{2}$, Pardayev T.U. ${ }^{1}$, Rakhmonov M.B. ${ }^{1}$ \\ ${ }^{1}$ Tashkent State Technical University, Uzbekistan \\ ${ }^{2}$ Termez branch of Tashkent State Technical University, Uzbekistan \\ Email: red engineer94@mail.ru
}

\begin{abstract}
The article presents the results of research work on the development of a technology for the reduction of wolfram oxides in a plasma installation. Distinctive features of energy supply to the reaction zone on a new type of plasma-chemical reactor for hydrogen reduction of tungsten and molybdenum oxides are presented. Energy is introduced not only in the form of a plasma jet but also in the form of an additional flow of gas heated to a high temperature, entering the reaction zone through a porous, permeable wall heated by an electric heater.
\end{abstract}

Keywords: Plasma installation, Reduction, Hydrogen, Raw material, Wolfram oxide, Tungsten, Molybdenum oxide, Molybdenum, Technology, Powder, Fine powder, Hard alloy.

\section{Introduction}

The modern development of science and technology requires further development and the widespread introduction of new highly efficient processes for obtaining refractory metals. These include the plasma-chemical technology for producing highly dispersed powders. The practical implementation of the plasma-chemical method for the production and processing of highly dispersed powders is at the initial stage.

Along with this, the need for processing structural materials with improved physical and mechanical properties is constantly growing. Such materials have low machinability due to their high hardness and strength at high temperatures, which leads to intense wear of the carbide cutting tool. To increase productivity in the processing of hard-to-machine materials, it is necessary to increase the durability of carbide tools, which can be ensured due to the use of new grades of hard alloys obtained from tungsten nano powders in a plasma installation [1].

Plasma-chemical technology in comparison with traditional technology has some significant advantages, namely, significant productivity, energy savings, environmental friendliness, and the possibility of complete mechanization and automation.

Ultrafine powders (UFP) of tungsten are widely used in traditional technology for the production of products and semi-finished products. On their basis, materials were obtained that, in terms of their physical and mechanical characteristics, significantly exceed serial products.

\section{Object and Research Methods}

Reducing plasma installation (PUV - 300) is the prototype of serial plasma installations and is operated in the research and production association for the production of rare metals and hard alloys at JSC Almalyk MMC (Figure 1).

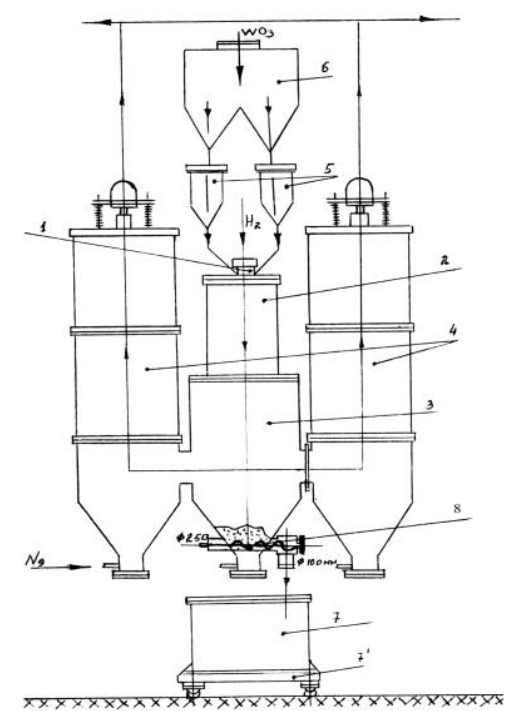

Figure 1: Scheme of a plasma reduction plant (PUV 300): 1 - plasma generator; 2 - reactor - 1 piece; 3 settling chamber; 4 - filter unit; 5 - powder feeders; 6 bunker for raw materials; 7 and $7^{1}$ - receiving hopper, consisting of a container and a trolley; 8 - auger.

The raw material is fed by pneumatic transport to the hopper (6), from which, under the influence of its weight, it continuously enters the feeders (5). From 
the feeders, the raw material with the help of the transporting gas - hydrogen $\left(\mathrm{H}_{2}\right)$ is fed through the input unit into the plasma jet into the reactor (2), where the raw material is mixed with the plasma jet, heating, melting - evaporation, the chemical reduction reaction, and powder condensation. Moving along the reactor, the powder particles collide with each other, forming conglomerates (lumps), which fall out of the steam-gas flow and accumulate in the lower part of the settling chamber (3). The smallest particles of the powder are carried with the steam-gas flow to the filters (4), where the mixture is purified from the powder. The cleaned steam-gas flow is directed to a candle or a shop-floor circulating hydrogen collector for regeneration and further use. The unit provides for the separation of the resulting powders into ultra dispersed and submicron powders. There are two points of unloading: 1) settling chamber; 2) filter.

The fraction of the powder that is collected in the settling chamber contains a certain amount of suboxides and therefore the content of oxygen and water vapor is $5-10 \%$ (weight). The average particle size is within the range of $0.8-1.0$ microns. Tungsten anhydride at the PUV-300 unit is reduced according to the regime given in table 1 .

Table 1. Tungsten anhydride reduction mode

\begin{tabular}{|c|c|c|}
\hline № & Parameter name & Norm \\
\hline 1 & Arc current, kA & from 0.45 to 0.55 \\
\hline 2 & Arc voltage, $\mathrm{V}$ & from 380 to 410 \\
\hline 3 & Hydrogen consumption through the plasmatron, $\mathrm{m}^{3} / \mathrm{h}$ & from 60 to 70 \\
\hline 3 & $\begin{array}{l}\text { Hydrogen consumption for transportation } \\
\text { tungsten anhydride, } \mathrm{m}^{3} / \mathrm{h}\end{array}$ & from 2 to 4 \\
\hline 4 & Plasma torch water consumption, $\mathrm{m}^{3} / \mathrm{h}$ & from 2,15 to 3,6 \\
\hline 5 & $\begin{array}{l}\text { High pressure manifold water pressure, Pa } \\
\mathrm{kgf} / \mathrm{sm}^{2}\end{array}$ & $\begin{array}{l}8,73 \times 10^{5}-11,77 \times 10^{5} \\
9-12\end{array}$ \\
\hline 6 & $\begin{array}{l}\text { The difference in temperatures of softened water at the inlet } \\
\text { and outlet of the plasma torch, }{ }^{\circ} \mathrm{C} \text {, no more }\end{array}$ & 20 \\
\hline 7 & $\begin{array}{l}\text { Gas pressure in the installation, } \mathrm{Pa} \text {, no more } \\
\mathrm{kgf} / \mathrm{sm}^{2} \text {, no more }\end{array}$ & $\begin{array}{l}0,98 \times 10^{4} \\
0,1\end{array}$ \\
\hline 8 & $\begin{array}{l}\text { Pressure of softened water at the inlet to the water distribution } \\
\text { manifold, } \mathrm{Pa}, \mathrm{kgf} / \mathrm{sm}^{2}\end{array}$ & $\begin{array}{l}78,48 \times 10^{4} \\
8\end{array}$ \\
\hline 9 & $\begin{array}{l}\text { Industrial water pressure in a low-pressure water supply } \\
\text { system, } \mathrm{Pa}, \mathrm{kgf} / \mathrm{sm}\end{array}$ & $\begin{array}{l}16.62 \times 10^{4}-39,24 \times 10^{4} \\
2-4\end{array}$ \\
\hline 10 & $\begin{array}{l}\text { Hydrogen pressure in the gas pipeline at the inlet to the gas } \\
\text { distribution manifold, } \mathrm{Pa} \text {, not less than } \mathrm{kgf} / \mathrm{sm}^{2} \text {, not less }\end{array}$ & $\begin{array}{l}3,9 \times 10^{4} \\
0,4\end{array}$ \\
\hline 11 & $\begin{array}{l}\text { The pressure of softened water at the outlet of the plasma } \\
\text { torch, } \mathrm{Pa} \text {, not less, kgf / } \mathrm{sm}^{2} \text {, not less }\end{array}$ & $\begin{array}{l}(-1,76) \times 10^{4} \\
(-1,18)\end{array}$ \\
\hline
\end{tabular}

The resulting powders are used in the following types of products:

- powders of grade 1.9 - 2.2 for the metallization of ceramics;

- powders of tungsten grades PVV, PVO, PV 1, PVPV, and others for the production of technical tungsten powders.

\section{Research Results}

A new type of plasma-chemical reactor for hydrogen reduction of tungsten and molybdenum oxides has a distinctive feature of supplying energy to the reaction zone. Energy is introduced not only in the form of a plasma jet but also in the form of an additional stream of gas heated to a high temperature, entering the reaction zone through a porous, permeable wall heated by an electric heater.
A new type of plasma-chemical reactor was created based on the following considerations. The process of plasma-chemical reduction in an ordinary reactor, in which $\mathrm{d} / \mathrm{D}$ is $1 / 10$, is divided by no more than $0.03 \mathrm{sec}$, and the plasma flow in a free flow in a large volume quickly loses its reserves of thermal energy, therefore, some of the powder that has fallen into the peripheral region of the jet remains unrecovered. Thus, it is necessary to extend the residence time of the tungsten oxide particles in the hot zone.

The structural diagram of the plasma-chemical reactor is shown in fig. 2 . Plasma jet with a diameter of $30-40 \mathrm{~mm}$ is compressed by a porous molybdenum tube with an inner diameter of 40-50 $\mathrm{mm}$, which is located coaxially in a porous tube made of stainless steel. A molybdenum heater is located between the porous tubes for heating the passing gas. 


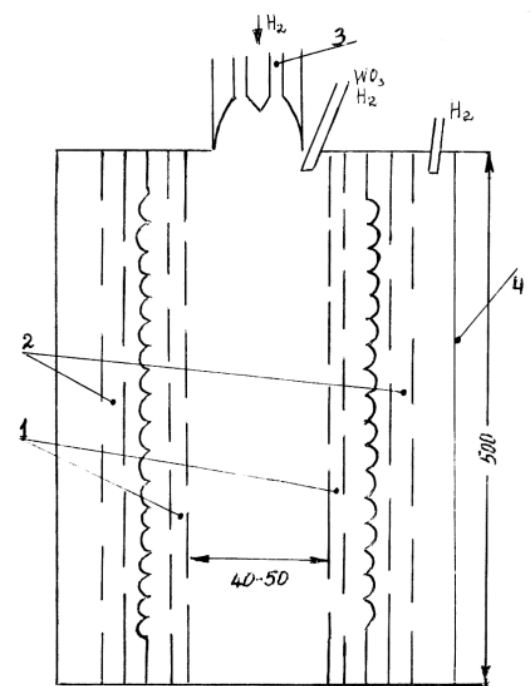

Figure 2: Structural diagram of a plasma-chemical reactor with an increased degree of processing of raw materials: 1 - porous cylinder made of molybdenum; 2 - porous stainless-steel cylinder; 3 - plasmatron A-26

$$
\text { (PG-2, I); } 4 \text { - casing. }
$$

The above-described structure is placed in a sealed casing, into which additional hydrogen is injected, which, being heated between the porous tubes, compresses the plasma jet. The complex of studies carried out on a semi-industrial plant made it possible to issue a technical assignment for the restoration of an experimental industrial plasma plant (PUV-300) with a capacity of $300 \mathrm{~kW}$ (Figure $3)$.

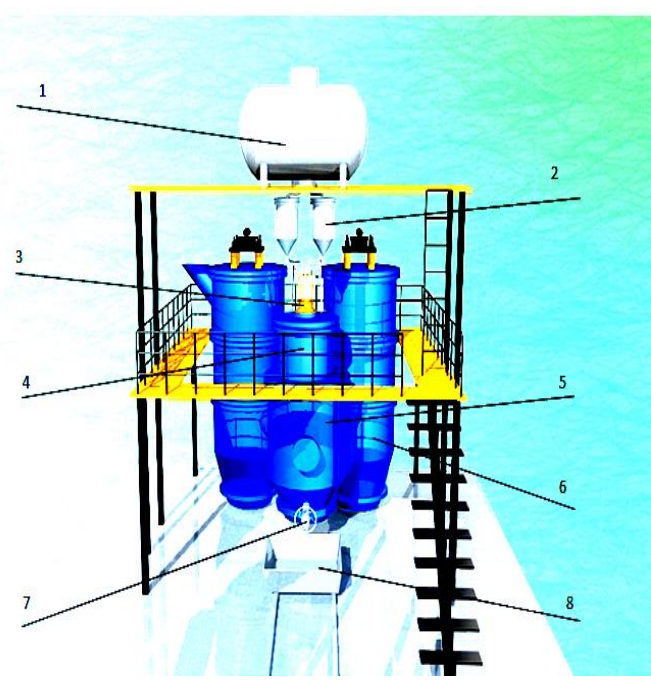

Figure 3: Reducing plasma installation (PUV - 300): 1 raw material hopper; 2 - powder feeders; 3 - plasma generator; 4 - reactor; 5 - cooling chamber; 6 - filter unit; 7 - auger; 8 - receiving hopper, consisting of a container and a trolley.
Due to the lack of raw materials, the plasmachemical installation stood for a long time. Cracks on the magnet were found in the installation during preparation for the launch. During the operation of the unit, the required pressure level was not reached [2].

The magnet material was subjected to a comprehensive study. The microstructure of the magnet was examined using a microscope. The structural state of the magnet for PUV-300 is shown in Fig. 4.

The normal course of the reduction of tungsten trioxide (Fig. 5) can be ensured when:

1) the average mass temperature of the hydrogen jet at the plasma torch exit is higher than $3200-3300$ $\mathrm{K}$;

2) uniform supply of raw materials from the feeder with the possibility of additional loading without switching off the plasma torch;

3 ) the absence of a skull on the units of the installation;

4) continuous or periodic removal of the product from the installation without depressurization;

5) a stable supply of hydrogen to the plasmatron with a pressure fluctuation of no more than $20 \%$;

6) the temperature of the cooling water is not higher than 25-300C.

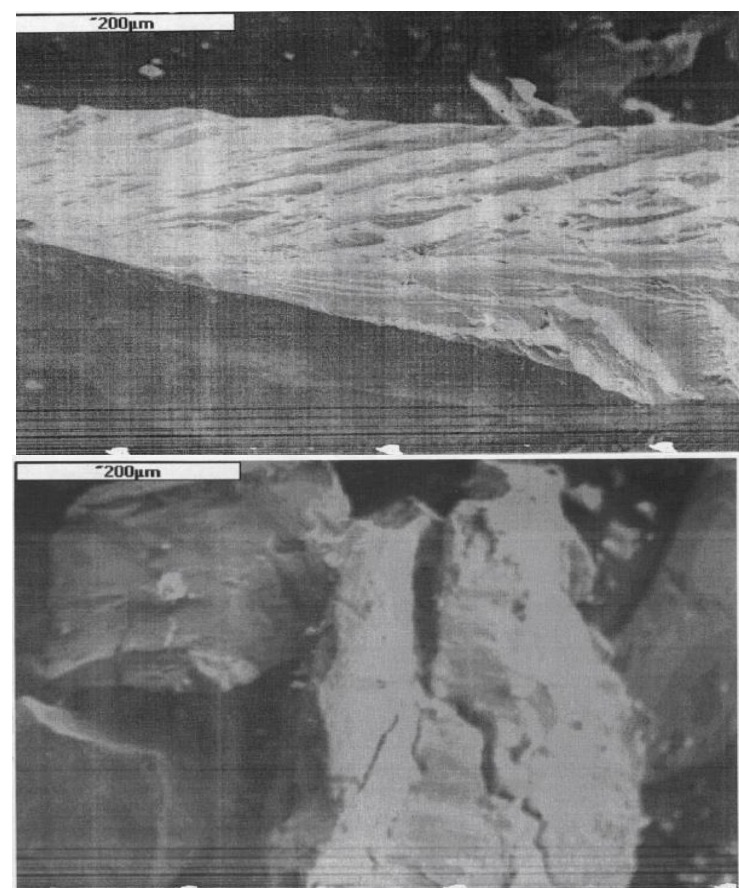

Figure 4: Structural state of a magnet for PUV-300. $x 180$

The production of metals and the reductive synthesis of their compounds with carbon, nitrogen, boron, silicon provide much wider possibilities for the use of low-temperature plasma. 


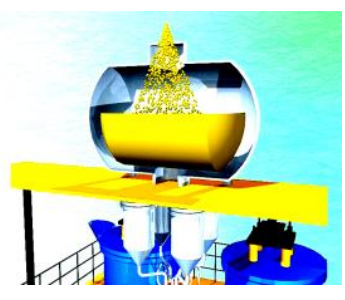

a)

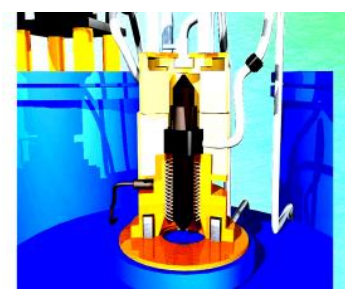

e)

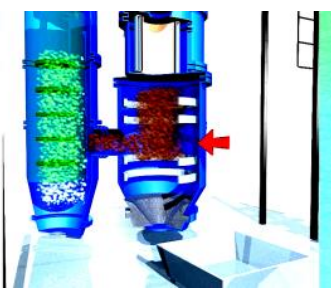

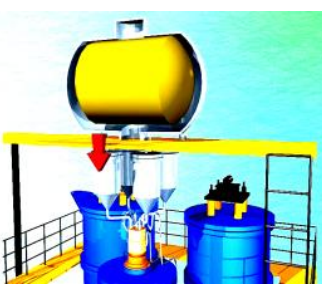

b)

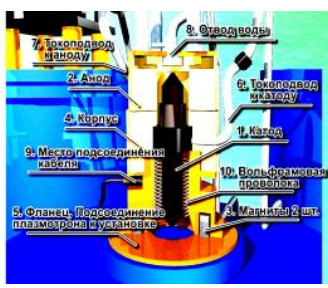

f)

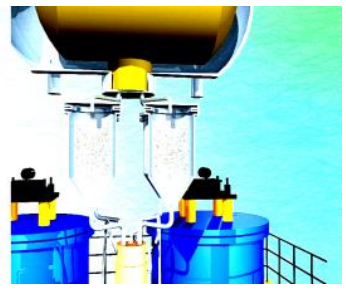

c)

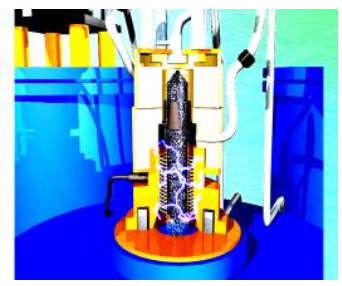

g)

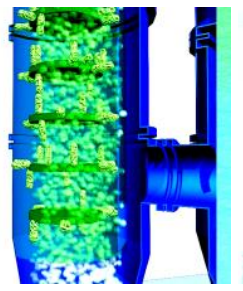

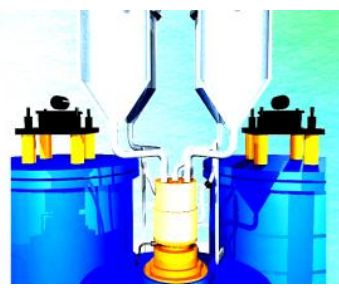

r)

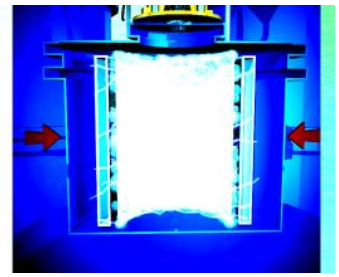

h)

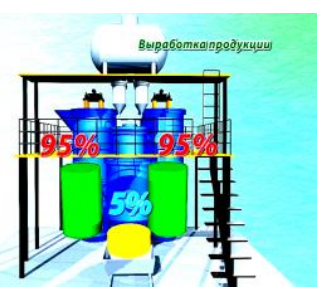

Figure 5: Principles of operation of the PUV-300 installation: a-bunker for raw materials; the b-the process of feeding raw materials to the feeders; $c$-feeders; r-plasma generator; $e, f, g$ - processes occurring in the plasma generator; h-reactor; and, $k, l$ - processes occurring in the filters; $m$ - general view of «PUV-300»

This is due not only to an extensive range of raw materials and products but also to smaller production volumes, as well as increased requirements for its environmental friendliness.

All versions of existing reducing plasma units in this area can be divided into two main groups: in the first, the processes take place in a liquid bath with a shaft-type plasma gasifier. In the second, the formation of the target product is carried out in a gas-dispersed flow when mixed with a plasma jet. Raw materials in both cases can be introduced into the high-temperature zone of the apparatus in the form of vapor, melt, solution, or powder of the required size. Plasma furnaces with a ceramic bath have sufficient versatility, and therefore many of them, tested in ferrous metallurgy, are successfully used to obtain non-ferrous metals such as nickel, cobalt, magnesium, vanadium, molybdenum, tin, tungsten, etc.

A new type of plasma-chemical reactor (Fig. 6) for hydrogen reduction of tungsten and molybdenum oxides has a distinctive feature of supplying energy to the reaction zone. Energy is introduced not only in the form of a plasma jet but also, in the form of an additional stream of gas heated to a high temperature, entering the reaction zone through a porous, permeable wall heated by an electric heater.

Figure 6 shows a longitudinal section of a plasmachemical reactor; coaxial cylinders, top view, section A-A; coaxial cylinders, section B-B and contains housing 1 , plasma generator 2 , nozzles with nozzles 3 , located in the upper part of the housing, in the area of the inner cylinder, for supplying a mixture of reagents - refractory metal anhydride with a gaseous reagent to the plasma jet, nozzle 4 for injection gaseous reagent into the wall cavity of the housing 1 . In housing 1 , along its central axis, there are coaxially installed two floors of the cylinder 5 and 7 . In-cylinder 5 installed in the center, along its entire surface, tangential holes 5 are made in a checkerboard pattern, which functions as nozzles for supplying a gaseous reagent.

Technological studies of the new reactor were carried out at the plasma installation. The power of the plasmatron was maintained within $45-55 \mathrm{~W}$, the power of the heater was $15-18 \mathrm{~kW}$, the hydrogen consumption through the plasma generator was 20 $\mathrm{m}^{3} / \mathrm{h}$, through the heater from 40 to $50 \mathrm{~m}^{3} / \mathrm{h}$. 
Tungsten oxide consumption is $5-10 \mathrm{~kg} / \mathrm{h}$. The temperature of the hydrogen heated by the heater is $1500{ }^{\circ} \mathrm{C}$.

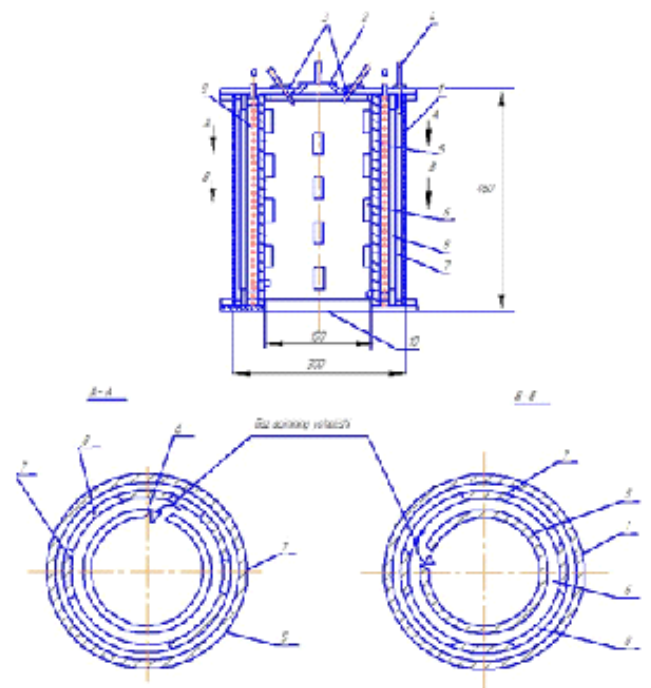

Figure 6: A new type of plasma-chemical reactor: 1case, 2-plasma generator, 3-coaxial cylinders, 4nozzle, 5,7-cylinders, 5-holes, 8-slot, 9-electric heater, 10-outlets

Thus, the total power was no more than $75 \mathrm{~kW}$, and the total hydrogen consumption was up to $80 \mathrm{~m}^{3}$ $/ \mathrm{h}$, while the plasmatron power according to the traditional scheme is $100 \mathrm{~kW}$ at a hydrogen consumption of $75 \mathrm{~m}^{3} / \mathrm{h}$.

Technological studies of the new reactor were carried out on a fortified plasma laboratory facility. The power of the plasmatron was maintained within 45-55 W, the power of the heater was 16-18 KW, the hydrogen consumption through the plasma generator was $20 \mathrm{~m}^{3} / \mathrm{h}$, through the heater from 40 to $60 \mathrm{~m}^{3} / \mathrm{h}$. Tungsten oxide consumption is $6-10 \mathrm{~kg} /$ h. The temperature of hydrogen heated by the air heater is $1500-1600{ }^{\circ} \mathrm{C}$. Thus, the total power was no more than $75 \mathrm{~kW}$, and the total hydrogen consumption was up to $80 \mathrm{~m}^{3} / \mathrm{h}$, while the plasmatron power according to the traditional scheme is $100 \mathrm{~kW}$ at a hydrogen consumption of 75 $\mathrm{m}^{3} / \mathrm{h}$.

The study of the obtained powders showed that the average grain size according to Fischer is 0.07 $0.09 \mu \mathrm{m}$ with an oxygen and moisture vapor content of $1.5 \mathrm{wt} \%$ (table 2).

$\mathrm{X}$-ray phase analysis showed the presence of $\beta$ tungsten up to $50 \%$, I - tungsten up to $35 \%$, and the rest is amorphous tungsten without the presence of oxide phases.

In the process of obtaining powders in a new reactor, practically no powder was found in the settling chamber under the reactor, which indicates that all the tungsten oxide supplied was reduced and the tungsten UFP fell on the filters [3].

The process of reduction of tungsten anhydride in a plasma-chemical reactor occurs in a plasma stream of hydrogen according to the reactions: (fig.1):

The plant has two powder discharge points

- settling chamber;

- filter.

As the powder accumulates in the settling chamber and filter, it is discharged into receiving containers. Depending on the type of raw material and the place of unloading, the following results are obtained:

- plasma reduction powder, unannealed (from the filter);

- powder of plasma reduction, unannealed (with a settling chamber).

Table 2. Fischer grain size and mass fraction of oxygen in powders obtained in a plasma-chemical reactor

\begin{tabular}{|c|c|c|c|}
\hline № & Sampling point & Fischer grain size, $\mathrm{mkm}$ & $\begin{array}{c}\text { Mass fraction of oxygen } \\
\text { and moisture vapor, } \%\end{array}$ \\
\hline 1 & W plasma. from the filter & 0,08 & 1,5 \\
\hline 2 & W plasma. from the filter & 0,09 & 1,5 \\
\hline 3 & W plasma. with settling chamber & 0,09 & $1-, 5$ \\
\hline 4 & W plasma. from the filter & 0,07 & 1,4 \\
\hline
\end{tabular}

$$
\begin{aligned}
& \mathrm{WO}_{3}+\mathrm{H}_{2}=\mathrm{WO}_{2.90}+\mathrm{H}_{2} \mathrm{O} \\
& \mathrm{WO}_{2.90}+\mathrm{H}_{2}=\mathrm{WO}_{2.72}+\mathrm{H}_{2} \mathrm{O} \\
& \mathrm{WO}_{2.72}+\mathrm{H}_{2}=\mathrm{WO}_{2}+\mathrm{H}_{2} \mathrm{O} \\
& \mathrm{WO}_{2}+\mathrm{H}_{2}=\mathrm{W}+\mathrm{H}_{2} \mathrm{O}
\end{aligned}
$$

Plasma reduction powder, unannealed from the filter, is black.

Plasma reduction powder, unannealed from the settling chamber - gray-black color.

- The powder should be free of cakes and lumps.
- The dispersion of the powder is characterized by the average particle size according to Fischer and should be no more than 0.4 microns. Loss of powder mass upon calcination in hydrogen is not more than $3 \%$. Reconstituted plasma powder has the following characteristics:

- oxygen content $0.5 \%$;

- average grain size according to Fisher 0.2-0.4 microns.

Plasma tungsten powders are intended for the production of tungsten powders of various grades, to 
improve the quality of products, to intensify the sintering process, fine-grained carbides, and hard alloys.

The use of the obtained UDP of tungsten as an alloying component of many high-temperature and heat-resistant materials and the production of products from them made it possible to improve the quality of these products, reduce the sintering temperature, and reduce energy consumption for the "Welding" operation.

The study used plasma tungsten powders taken from filters of an industrial installation PUV-300. The characteristics of plasma tungsten powders are given in the table 3 .

Table 3. Characterization of Tungsten Plasma Powders

\begin{tabular}{|c|c|c|c|}
\hline $\begin{array}{c}\text { Powder } \\
\text { Tungsten }\end{array}$ & Oxygen content in\% & Bulk density, $\mathrm{g} / \mathrm{sm}^{3}$ & Specific surface area, $\mathrm{m}^{2} / \mathrm{g}$ \\
\hline 1 & 2,0 & 0,70 & 4,0 \\
\hline 2 & 2,4 & 0,82 & 5,8 \\
\hline 3 & 3,0 & 0,90 & 8,0 \\
\hline
\end{tabular}

The oxygen content was calculated by the gravimetric method by annealing the powder in a stream of hydrogen at $900{ }^{\circ} \mathrm{C}$.

The bulk density was determined using a volume meter, and the specific surface area was determined by the thermal desorption of argon.

The powders were granulated in a drunk barrel system. Pressing of production samples on presses of the P474A, P807 brands. Working out of the modes of pressing, sintering, welding was carried out on the production equipment of shop 2 (PUV300 , TSEP-214, STN-1,6).

In the experiment, we used powders, which include, according to mass spectrometry data, gases: $\mathrm{O}_{2}, \mathrm{H}_{2}$, $\mathrm{W}_{2}, \mathrm{H}_{2} \mathrm{O}, \mathrm{CO}, \mathrm{CO}_{2}$.
Getting compact workpieces. The experiment was carried out on the initial ultrafine tungsten powders with the introduction of a plasticizer (alcohol, glycerin 1: 1) into their composition. Mixing of powders with a plasticizer and at the same time, their granulation was carried out on a vibrating mixer.

The formation of highly dispersed powders is associated with a sharp increase in the resistance to the punch due to friction along the walls. Therefore, it is practically impossible to obtain sticks without delamination during pressing. The use of impact pressing methods also does not lead to a positive result. The bulk density is given in the table. 4 .

Table 4. Bulk density

\begin{tabular}{|l|c|c|c|c|}
\hline \multirow{2}{*}{ Powder } & \multicolumn{3}{|c|}{ Ultrafine } & Standard \\
\cline { 2 - 5 } & original & sieved & granulated & sieved \\
\hline Bulk density W, g/sm & $0,7-0,9$ & $1,4-1,8$ & $2,0-2,2$ & $3,4-3,65$ \\
\hline
\end{tabular}

High-quality sticks are obtained from granular tungsten powders, the compaction process of which can be represented as follows: in the initial period of pressing, compaction occurs due to the movement of granules associated with the destruction of bridges and arches formed during free filling of the powder. This leads to an increase in stress at the contact points of the particles, which, in turn, causes irreversible elastic deformation and brittle fracture of the granules. Further compaction occurs according to the usual scheme by filling the voids with particles formed as a result of the destruction of the granules.

Presses with uniform density are obtained by the hydrostatic pressing of powders in elastic shells due to the manifestation of plastic deformation by brittle bodies under conditions of all-round compression.

Specificity of the formation and sintering of ultrafine tungsten powders. According to the recrystallize sintering mechanism based on the formation of an excess concentration of nonequilibrium vacancies during recrystallization, leading to a significant activation of self-diffusion processes. Shrinkage in the initial period of sintering proceeds according to two mechanisms of mass transfer: grain boundary sliding of particles and diffusion-viscous flow (liquid-like coalescence).

Shrinkage, in this case, will depend on the initial porosity of the compact, and the greatest will not necessarily be observed in compacts with minimum porosity. The data obtained show that the most favorable values of the pressing forces for ultrafine tungsten powders are in the range of 100-200 MPa.

Production of bars from ultrafine tungsten powders. $5 \%$ of a plasticizer was added to the finely dispersed tungsten powder, and the powder was granulated for an hour. The granular powder was pressed into sticks with a cross-section of $12 \times 12 \times 500$ at a force of $200 \mathrm{MPa}$. T

he compacting density was $10.2 \mathrm{~g} / \mathrm{cm}^{3}$. The sticks were sintered in a TSEP214 furnace at a 
temperature of $1373^{\circ} \mathrm{K}$ for two hours. The bars were welded according to the existing technology at various welding currents. Standard density can be obtained even at a welding current of $2.6 \mathrm{kA}$.

Table 5. The results of welding rods made of ultrafine tungsten powders

\begin{tabular}{|c|c|c|}
\hline $\mathrm{Wn} / \mathrm{n}$ & Welding current, $\mathrm{kA}$ & The density of the staff, $\mathrm{g} / \mathrm{cm}^{3}$ \\
\hline 1 & 2,2 & 17,0 \\
\hline 2 & 2,4 & 17,8 \\
\hline 3 & 2,6 & 17,9 \\
\hline 4 & 2,8 & 18,0 \\
\hline 5 & 3,0 & 18,2 \\
\hline
\end{tabular}

\section{Discussion}

Currently, the main requirements for wear-resistant cutting materials include high hardness and a homogeneous fine structure.

To equip metal-cutting tools, the industry produces alloys of the "M" type (VKZ-M, VK6-M, VK10-M) with a WC-phase grain size of 1.8 microns without alloying additives.

The new alloy under development has a higher hardness and wear resistance compared to existing alloys and will be designed for machining difficultto-machine materials.

The most effective methods for creating such an alloy are the use of ultrafine tungsten powders and intensive grinding of the WC phase.

\section{Conclusions}

Thus, based on the analysis of technological tests of the new plasma-chemical reactor, the following conclusions can be drawn:

- the degree of processing of raw materials is increased up to $95 \%$;

- received UDP much smaller and more active;

- the real amount of amorphous tungsten was found in the manufactured powders;

- increased controllability of the process, including the dispersion of the powder;

- the uniformity of the particle size distribution increases;

- the coefficient of the obtained action of the restoration process increases.

As a result of the conducted research, it was revealed that the developed alloy differs from standard fine-dispersed alloys with a fine-grained structure;

the volume of WC-phase grains up to $1 \mu \mathrm{m}$ in size is $80-85 \%$, and in VK10-M alloys - 65-75\%;

the average grain size of the WC-phase is 1.1 microns, and in the VK10-M alloy, it is 1.3-1.5 microns.

\section{References}

[1] Nurmurodov S.D., Rasulov A.Kh. Sozdanie konstrukcionnyh materialov $\mathrm{s}$ ispolzovaniem ultradispersnyh poroshkov volframa [Creation of structural materials using ultrafine tungsten powders]. Monografiya. Toshkent, ToshDTU, 2015 i. 168 str.

[2] S. D. Nurmurodov, A. Kh. Rasulov, N. D. Turahadjaev, K.G. Bakhadirov. Development of New Structural Materials with Improved Mechanical Properties and High Quality of Structures through New Methods Using New Type of Plasma Chemical Reactor. American Journal of Materials Engineering and Technology Vol. 3, No. 3, 2015, pp 58 -62.

[3] Nurmurodov S.D., Rasulov A.Kh., Asadov I.S., Ruziev U.N. i drug. Plazmohimicheskiy reaktor [Plasma-chemical reactor]. Patent, IAP 04732. 26/06/2013 g.

[4] S. D. Nurmurodov, A.Kh. Rasulov, Allanazarov A.A. Study of Morphology and Dimensions of Ultra Dispersed Powders of Tungsten by Crystal-Optical Method of Discharge. TEST Engineering Management Article Info, Volume 83, Page Number: 844 - 848, Publication Issue: March April 2020.

[5] S. D. Nurmurodov, A. Kh. Rasulov, N. D. Turahadjaev, K.G. Bakhadirov.Development of New Structural Materials with Improved Mechanical Properties and High Quality of Structures through New Method. Canadian Journal of Materials Science Research, Vol. 5, No. 3, 2016, pp $52-58$.

[6] Rasulov A.Kh., Nurmurodov S.D.,Mardanokulov Sh., Allanazarov A.A. Razrabotka tehnologii proizvodstva novogo spechennogo splava Mo-TiC [Development of technology for the production of a new sintered alloy Mo-TiC]. Materialy V Mejdunarodnoi studencheskoi nauchnoprakticheskoi konferencii. Omsk, 4-10 aprelya 2016g. Str. 138-142.

[7] Nurmurodov S.D., Rasulov A.Kh., Asadov I.S., Ruziev U.N. i drug. Plazmohimicheskiy reaktor [Plasma-chemical reactor]. Patent, IAP 04732. 26/06/2013 g. 
[8] Rasulov A.Kh., Khalimjonov T.S., Rasulova Sh.A., Ikromov J.T., Bekjonova V.B. Sozdanie matematicheskoy modeli, pozvolyayushey predskazivat dispersnost poluchaemogo poroshka tugoplavkogo metalla [Creation of a mathematical model that makes it possible to predict the dispersion of the resulting refractory metal powder]. I-aya Mejdunarodnaya nauchnoprakticheskaya konferenciya LIT'E I METALLURGIYA. Belorussiya. 15-16 noyabrya 2018 goda. Str. 108-109.

[9] Nokhudjayev Fayzulla Ramazonovich, Mukhamedov Azad Anvarovich, Teshaboyev Abduvakhob Marifovich, Usmonov Jasur Muminaliyevich, Parmonov Sarvar Toshpulatovich. Resource-saving manufacturing technologies and thermal hardening of machine parts and tool. International Journal of Mechatronics and Applied Mechanics (IJOMAM), 2021, Issue 9, and ISSN: 2559-6497, P 137-145.
[10] Ziyamukhamedova U.A., Bakirov L.Y., Rakhmatov E.A., Bektemirov B.Sh. Structure and Properties of Heterocomposite Polymeric Materials and Coatings from them Obtained by Heliotechnological Method. International Journal of Recent Technology and Engineering (IJRTE), ISSN: 2277-3878, Volume-8, Issue-3S, October 2019. P 399-402

[11] Norkudjayev F. R. Alikulov A. Kh. Abdurakhmonov Kh. Z. Tursunov T. Kh. Examination of Thermophysical Processes in the Creation of Metal Layered Compositions. International Journal of Recent Technology and Engineering (IJRTE) ISSN: 2277-3878, Volume-8 Issue-2S10, September 2019. P 361-366. https://www.scopus.com/record/display.uri?eid $=2$-s 2.0 -

85075285756\&origin=AuthorNamesList\&txGid= 5e9426dea9148b5d4943f35d019901c5 